\title{
Avanzando hacia una democracia participativa
}

\author{
Sebastián Becker Castellaro \\ Abogado, Chile
}

SOBRE Francisco Soto Barrientos y Yanina Welp, Los diálogos ciudadanos. Chile ante el giro deliberativo. Santiago, Lom, 2017.

\section{Introducción}

El libro Los diálogos ciudadanos. Chile ante el giro deliberativo se inserta, al mismo tiempo, en dos debates del derecho constitucional plenamente vigentes. En primer lugar, aborda la crisis de las democracias representativas en el mundo occidental, proponiendo mecanismos específicos y concretos para superarla. $\mathrm{Y}$, en segundo lugar, el libro se inserta en la discusión sobre el reemplazo de la Constitución Política chi-lena de 1980, proponiendo su propia hoja de ruta para una solución a la coyuntura constitucional.

Para entender las democracias representativas debe señalarse que éstas nacen producto de la inspiración liberal-burguesa que buscaba limitar los pode-res del Estado, asegurando la protección y seguridad de los ciudadanos para que éstos puedan desenvolverse libremente en el aparato estatal. De esta forma, las democracias representativas tienen como principal preocupación escoger a los más capaces para evitar la vuelta del bellum omnium contra omnes y una eventual tiranía de la mayoría.

Esta concepción elitista puede encontrarse no solo en Europa, sino además en Es-tados Unidos. Por ejemplo, el intelectual federalista Benjamin Rush señalaba que «es común escuchar que 'la soberanía y todo el poder está sentada en el pueblo'. Esta idea está infelizmente expresada. Debiese decir que el poder deriva del pueblo» (Kramer, 2004: 128; énfasis en el original). Detrás de esta frase subyace la idea que la soberanía provenía del pueblo y era delegada a los representantes; a su vez, éstos administraban el poder para que, solo en los periodos de elecciones, dicho poder volviera nuevamente al pueblo (Kramer, 2004: 129). 
La democracia representativa tiene su núcleo en conceder la soberanía al pueblo para que éste solamente escoja a sus representantes, es decir, que el pueblo escoja quién decide (Sartori, 2005: 33). Los gobernantes, por su parte, deberán ser las personas más idóneas y competentes dentro de la sociedad. La democracia representativa valora profundamente el mercado y la gobernanza de las instituciones (Young, 2000: 20), entendiendo la estabilidad como fundamental (Böckeförde, 200o: 143), mostrando que en esta concepción subyace una visión elitista, utilitarista y tecnócrata.

Sin embargo, a mediados del siglo XX, este modelo de democracia fue perdiendo fuerza en el mundo occidental. Aumentaron los niveles de abstención y apatía política, además de producirse un distanciamiento entre la ciudadanía y la clase política. Esto implicó un «riesgo de debilidad y merma de la legitimidad de las estructuras democráticas» (Martí, 2006: 13). Las protestas en contra del establishment y el desencanto con las autoridades, en palabras de Martí, viene dada por «el extremo individualismo de las sociedades capitalistas modernas, promovido a su vez por el modelo liberal y no intervencionista de la democracia» (Martí, 2006: 13).

Welp y Soto son conscientes de lo anterior. De hecho, lo manifiestan explícitamente, señalando que la desconexión entre la ciudadanía y los clásicos canales de transmisión de demandas hace repensar «las fuentes de legitimación del sistema político» (Welp y Soto, 2017: 32). Así unas de las tesis señaladas en el texto es que las democracias:

no pueden eludir la incorporación y activación de mecanismos de participación ciudadana, ya que estos son fundamentales para fortalecer la capacidad de respuesta a las demandas de la población - una población heterogénea y con demandas diversas, a menudos divergentes $-\mathrm{y}$, consecuentemente, la legitimidad de los sistemas políticos (Welp y Soto, 2017: 35).

Por consiguiente, el libro pretende mediante la participación lograr una superación al estado de crisis general que viven las clásicas democracias representativas.

Por otro lado, el libro se inserta de lleno en la discusión nacional sobre el reemplazo de la Constitución Política chilena. Welp y Soto caracterizan a Chile como un país carente de una estructura fuerte que legitime de forma robusta a los representantes políticos. Dado lo anterior, vinculan a la Constitución de 1980 y a su sistema representativo - porque claramente Chile no escapa de la crisis señalada en los párrafos anteriores- con «una pérdida creciente de legitimidad» (Welp y Soto, 2017: 98) debido a un sistema constitucional que no promueve una verdadera competencia electoral y otorga un amplio margen de discrecionalidad a las autoridades representativas.

De este modo, es interesante destacar que los autores consideran que «el objetivo final del modelo establecido bajo la Constitución de 1980 es reducir al mínimo la deliberación, afectando en consecuencia la participación y la legitimidad del sistema» 
(Welp y Soto, 2017: 98). Esto ha sido ya esbozado por otros autores (Atria, 2013: 37), lo que muestra una tendencia doctrinaria clara al respecto.

Welp y Soto consideran que son causas endógenas a la Constitución de 1980 las que motivan finalmente su reemplazo, y no una vorágine política coyuntural. Es decir, nació para ser reemplazada por una que sí tenga la legitimidad de sus ciudadanos y ciudadanas (¿una Constitución de transición?).

Así las cosas, en una primera mirada el libro, se inserta de lleno en discusiones del todo atinadas y contingentes, entregando un análisis pormenorizado de los debates recién expuestos y comprendiendo de forma inteligente e informada los nudos de las problemáticas doctrinales sobre la crisis de las democracias representativas y un eventual reemplazo de la Constitución chilena de 1980.

\section{Pertinencia de las ideas: Asamblea Constituyente y giro deliberativo}

Dicho lo anterior, cabe resaltar las principales ideas del libro a propósito de los contextos ya explicados.

Como se señaló, el principal foco del libro es repensar los sistemas democráticos representativos para fortalecerlos y otorgarles mayor músculo legitimador a los pro-cesos políticos que éstos viven. Para ello, el objetivo que tienen los autores es ilustrar que a través de procesos deliberativos autónomos es posible fortalecer el capital po-lítico y dotar a los representantes de nuevas posiciones políticas a defender (Welp y Soto, 2017: 35). La participación sería el motor que lleve adelante estos nuevos pro-cesos, como un complemento a las democracias representativas, para "producir me-jores argumentos y conducir a decisiones que cuenten con mayor legitimidad y den respuestas más apropiadas a las demandas ciudadanas» (Welp y Soto, 2017: 63).

La propuesta de Welp y Soto está dada por entender la participación como una válvula de escape frente a la crisis que tienen las democracias representativas y que, mediante instituciones participativas, se permita crear nuevos canales que refuercen las decisiones políticas, dotando de nuevos argumentos y nuevos actores a las elitizadas decisiones políticas. Por consiguiente, la propuesta da cabida a mayores iniciativas ciudadanas que permitan presentar leyes y votarlas, siempre que éstas se discutan por mecanismos apropiados y no controlados por los gobiernos de turno (Welp y Soto, 2017: 64). ${ }^{1}$

Otro de los puntos fuertes del libro es en cuanto a la participación en procesos constituyentes. El libro realiza un estudio comparado a las experiencias latinoame-

1. Lo anterior parece fundamental: en un estudio comparado, la participación se observa amenazada por gobiernos autoritarios que pretenden manipular procesos ciudadanos a su favor. Véase, en este sentido, Negretto, 2015: 210-211. 
ricanas y europeas que permiten dar luces en cómo debiera ser un proceso constitucional chileno y las fórmulas existentes para realizar un reemplazo constitucional sin terminar en un desastre institucional.

El libro pretende desmitificar y espantar un sinnúmero de falacias que se han esgrimido en torno a las asambleas constituyentes, desde profesores de derecho que señalan que «lo que ha pasado en Venezuela podría repetirse en Chile en caso que, como quieren algunos, se convoque a una AC (Asamblea Constituyente)» (Soto, 2017), ${ }^{2}$ hasta medios de comunicación masivos que señalan, entre otras cosas, que «una AC llevaría a un gobierno autoritario de izquierda, como en Venezuela». ${ }^{3}$ Los capítulo cuarto y quinto de este libro («Orígenes y mitos de la asamblea constituyente: la experiencia latinoamericana» y «La participación ciudadana en procesos constituyentes», respectivamente) pretenden defender una discusión seria sobre un eventual reemplazo constitucional en Chile en base a la experiencia comparada, con una sólida óptica de derecho constitucional.

En este sentido, el texto realiza una síntesis de los estudios de Elster, Gingsburg, Loewestein, Schmitt y otros autores, destacando cómo, desde la dogmática jurídica constitucional, se ha sustentado la idea de la Asamblea Constituyente (en adelante, AC); incluso, quizás como un guiño a la derecha conservadora chilena, rescata a Hayek como un defensor de la AC como mecanismo legitimador del proceso de independencia estadouniden-se (Welp y Soto, 2017: 113).

De este modo, una de las cuestiones más notables del libro es el estudio en torno a la $\mathrm{AC}$ en la experiencia latinoamericana: doce países de la región utilizaron este mecanismo para reemplazar su constitución y solo dos (Argentina y Bolivia) tenían regulado este mecanismo para su reemplazo en sus cartas fundamentales previas (Welp y Soto, 2017: 117). De la misma manera, el libro resalta la labor de los tribunales constitucionales como actores claves para definir el éxito o fracaso de los reempla-zos constitucionales, destacando que, en la experiencia comparada, el fracaso de los gobiernos en este sentido fue de la mano de la falta de apoyo de los tribunales cons-titucionales nacionales (caso de India, República Checa o Nicaragua) (Welp y Soto, 2017: 118).

Así, los autores concluyen que «la AC surge de la mano del constitucionalismo, del derecho público y el Estado liberal» (Welp y Soto, 2017: 131), contestando concretamente cuatro falacias presentes en el debate público chileno: «i) que es factible implementar la AC ignorando los procedimientos de reforma vigentes; ii) que la $\mathrm{AC}$ es la solución mágica o una amenaza radical; iii) que la $\mathrm{AC}$ es el único mecanismo

2. Sebastián Soto, «No + AC», La Tercera, 29 de agosto de 2017, disponible en http://www.latercera. com/voces/no-ac/.

3. Véase la infografía «El Mercurio vs. Asamblea Constituyente. Seis falacias de El Mercurio sobre la AC», en el sitio de Fundamental, disponible en http://bit.ly/2EwKftg. 
que garantiza la participación ciudadana; y iv) la AC está cuestionada por el derecho comparado» (Welp y Soto, 2017: 131).

Por otro lado, otra de las novedades del libro es la exploración dogmática en torno a la participación en procesos constituyentes. Esta clase de participación no está consagrada de manera robusta en la dogmática constitucional y la conceptualización de participación constitucional presenta una verdadera innovación teórica. De este modo, los autores - siguiendo la experiencia comparada - dividen la participación constitucional en procesos participativos ex ante, procesos participativos durante la constituyente y referendos de ratificación (Welp y Soto, 2017: 137-142).

Sumado a ello, los autores entienden que la participación debe ir acompañada de un estudio sobre cómo y qué se está deliberando. Destacan que debería realizarse una receptividad deliberativa que permita incorporar en los tópicos de la discusión pública y en la elaboración de una nueva constitución las participaciones que se realizan, generando un valor añadido y de legitimidad a los procesos constituyentes (Welp y Soto, 2017: 143-144).

Asimismo, realizan un estudio pormenorizado de las principales experiencias comparadas, extrayendo lecciones que permiten iluminar el proceso constituyente chileno. En primer lugar, destacan que son necesario metodologías para procesar los inputs derivados de la participación, debido a que no es posible mejorar las decisiones políticas si es que no existe una organización de los mecanismos participativos deliberativos (¿la sistematización de los Encuentros Autoconvocados podrá ser una buena respuesta?) (Welp y Soto, 2017: 162). En segundo lugar, se necesita un diseño a largo plazo que brinde a los nuevos actores nuevos mecanismos concretos para deliberación, y que se incorporen orgánicamente en los debates públicos de acuerdos y desacuerdos de la élite (Welp y Soto, 2017: 163).

Finalmente, el libro desarrolla una explicación in situ de la experiencia chilena de participación en el proceso constituyente. Explica detalladamente los pasos que ha impulsado el Gobierno de Michelle Bachelet para llevar adelante el proceso constituyente y las experiencias políticas con que el Consejo de Observadores ha tenido que lidiar para llevar adelante su labor. En este sentido, cabe decir que el libro es optimista frente al proceso de participación ciudadana chileno, en cuanto pueda «incorporar nuevos tópicos en la discusión constitucional y construir legitimidad desde abajo» (Welp y Soto, 2017: 190). Sumado a ello, el libro aporta algo que parece sumamente relevante para el proceso constituyente nacional: no existen regulaciones comparadas que permitan establecer mecanismos concretos de participación en los procesos de reemplazo constitucional (Welp y Soto, 2017: 197). 


\section{Reflexiones finales}

A la luz de lo señalado, la posibilidad de dotar de mayor legitimidad un sistema democrático representativo o reemplazar una Constitución a través de la participación no parece simple. Si bien existen procesos constituyentes con grandes procesos participativos, como los de Brasil y Ecuador, la falta de metodologías claras en el proceso deliberativo ha llevado a la decepción de ciudadanos y ciudadanas con las formas de gobierno (piénsese en la disputa indígena contra el Gobierno de Correa en Ecuador o el caos institucional que vive Brasil). Sin embargo, el texto acá presentado propone un avance: es necesario explorar mecanismos que permitan sistematizar los procesos de participación deliberativos para utilizarlos como herramientas de accountability de los gobiernos que impulsan cambios constitucionales; esto será un paso hacia delante y un verdadero complemento a las democracias representativas, de modo que se vuelvan más participativas.

De esta forma, cabe entonces preguntarse si los mecanismos de participación servirán finalmente como herramientas para exigir contenidos a la discusión que tienen nuestras autoridades, cristalizando de forma más fidedigna el principio de la soberanía popular. Y en el caso chileno, ¿ será la sistematización realizada en los Encuentros Autoconvocados la herramienta que la sociedad civil y la ciudadanía tenga para exigirle al Gobierno (o la autoridad de turno) que incorpore demandas ciudadanas a una nueva Constitución? Si bien el libro tiene esperanzas que ello se dé, habrá que esperar a la ciudadanía para dar una respuesta.

\section{Referencias}

Atria, Fernando. (2013). La constitución tramposa. Santiago: Lom.

Böckeförde, E. W. (2000). «Democracia y representación. Crítica a la discusión actual sobre la democracia» En Estudios sobre el Estado de Derecho y la democracia. Madrid: Trotta.

Kramer, Larry (2004). The People Themselves: Constitutionalism and Judicial Review. Nueva York: Oxford University Press.

Martí, José Luis (2006). La República deliberativa. Barcelona: Marcial Pons.

Negretto, Gabriel (2015). «Procesos Constituyentes y Refundación democrática. El caso de Chile en perspectiva comparada». Revista de Ciencia Política, 35 (1): 201-215. SARtori, Giovanni (2005). «En defensa de la representación política». En Miguel Carbonell (compilador), Democracia y representación: Un debate contemporáneo. México D.F.: Tribunal Electoral del Poder Judicial de la Federación.

WeLP, Yanina y Francisco Soto (2017). Los diálogos ciudadanos. Chile ante el giro deliberativo. Santiago: Lom.

Young, Iris (2000). Inclusion and Democracy. Nueva York: Oxford University Press. 


\section{Sobre el autor}

Sebastián Becker Castellaro es abogado. Licenciado en Ciencias Jurídicas y Sociales de la Universidad de Chile. Tesista de Magíster en Derecho con mención en Derecho Público de la Facultad de Derecho de la Universidad de Chile. Becario del Programa de Perfeccionamiento Académico Facultad de Derecho, Programa de Magíster en Derecho con y sin mención (2015-2017). Su correo electrónico es sebastian. becker.castellaro@gmail.com. 
